\title{
Studies on Processing and Characterization of Hydroxyapatite Biomaterials from Different Bio Wastes
}

\author{
Sudip Mondal ${ }^{1,2 *}$, Biswanath Mondal ${ }^{1}$, Apurba Dey ${ }^{2}$, Sudit S. Mukhopadhyay² \\ ${ }^{1}$ Centre for Advanced Material Processing, Central Mechanical Engineering Research \\ Institute,Mahatma Gandhi Avenue, Durgapur-713209, India \\ ${ }^{2}$ Department of Biotechnology, National Institute of Technology, Mahatma Gandhi Avenue \\ Durgapur-713209, India
}

Corresponding Author: mailsudipmondal@gmail.com; Phone: +917384212023

\begin{abstract}
Development of suitable materials that acts as an interface between the implant and tissues in body system structurally, mechanically and bio functionally is important for the success of tissue engineering. This motivated materials scientists and biologists to find out suitable bioactive materials for the aforementioned purpose. There has been growing interest in developing bioactive synthetic ceramics that could closely mimic natural apatite characteristics. Hydroxyapatite (HAp) has been widely used as a biocompatible ceramic but mainly for contact with bone tissue, due to its resemblance to mineral bone. This study presents the synthesis and characterization of HAp materials from different sources like bovine bone and fish scales and their application in tissue engineering. The phase purity and crystallinity of different calcined HAp powder was determined by XRD and FTIR analysis. The Thermo Gravimetric and Differential Thermal Analysis were carried out to show the thermal stability of the HAp powder. The morphology of the powder was observed under Scanning Electron Microscopy (SEM). Cytotoxicity evaluation of the developed powder was carried out in RAW macrophage like cell line media for an incubation period of 72 hours. These results proved the biocompatibility of HAp powders obtained from different biosources for tissue engineering applications.
\end{abstract}

Key words: Hydroxyapatite; Biomaterials; Tissue Engineering; Cytotoxicity; 


\section{INTRODUCTION}

Hydroxyapatite $\left[\mathrm{Ca}_{10}\left(\mathrm{PO}_{4}\right)_{6}(\mathrm{OH})_{2}\right]$ has been acknowledged as a bone graft material in a range of medical and dental applications due to their similar chemical composition with natural bones. Generally, bone substitution materials such as autograft, allograft and xenograft are used to solve problems related to bone trauma and fractures. But, none of these materials provide a perfect replacement of the bone due to mechanical and biological instability and incompatibility. Recently, calcium phosphate bio ceramics such as calcium phosphate, tri-calcium phosphate and HAp are identified as most suitable bone substitution materials to serve the demand. Unlike other calcium phosphates, HAp does not break under physiological conditions. In fact, it is thermodynamically stable at physiological $\mathrm{pH}$ and actively takes part in bone bonding. This property has been exploited for rapid bone repair after major trauma or surgery. HAp is derived from natural materials such as coral and fish bone (Jensen et al., 1996), fish scale (mondal et al. 2010). Attempts have been taken to isolate fish scale derived HAp and use them as an alternate for synthetic HAp (mondal et al. 2010). Generally, very high heat treatment $\left(1250^{\circ} \mathrm{C}\right)$ is used for isolation of HAp from fish scale and this temperature gives a higher strength to HAp structure (Choi, Lee, Jeon, Byun, \& Kim, 1999) and results an excellent biocompatible inorganic substance (Kim et al., 1998; Kim \& Park, 2000; Kim, Park, \& Kim, 2001). HAp and calcium phosphate based materials have attracted considerable interest in the field of Tissue Engineering because of similarities with the mineral fraction of natural bone and high biocompatibility with living tissues. It has good bio affinity, stimulates osteo conduction and is slowly replaced by the host bone after implantation. Application of the HAp biomaterial as a porous or granulated material useful in bone surgery or coating on metallic bio implants. A number of methods have been used for HAp powder synthesis such as solid state reaction, hydrothermal reaction, coprecipitation reaction, sol-gel synthesis, mechano-chemical synthesis etc [1-5]. Natural structural HAp material from fish scale [6] and bovine bone not only provide an abundant source for novel bone and cartilage replacement but it also inspires investigations to develop biomimetic composites.

In this study HAp powder was synthesized from fish scales. Fish scales are mainly composed of collagen, connective tissue proteins, water and the remaining $41 \%$ to $84 \%$ [7] of other proteins. In course of evolution, scale formation process shows the same mechanism as in the formation of teeth and bone. This study shows that the biomimetic property may lead to the development of new biomaterials. There are several types of calcium phosphate salts, which are present in fish scales due to their extreme biological response in physiological environment. HAp powder was extracted by calcining the chemically treated fish scales at different temperatures. Extraction of HAp from bovine bone is biologically safe and economic, since it is easy to obtain. Bone is a unique composite, containing a collagenous hydrogel matrix consisting of about 33-43\% apatite minerals, 32-44\% organics, and 15-25\% [8] water on a volumetric basis. HAp material manufactured from bovine bones has the advantage of inheriting some properties of the raw materials viz. its chemical composition and structure. The synthesized powder from these two 
different bio sources are ball milled for several hours and compacted. The Thermo GravimetricDifferential Thermal Analysis, X - ray diffraction (XRD), Fourier Transform Infrared spectroscopy (FTIR) were employed to characterize the synthesized powder. The morphology of the derived HAp powder has also been studied by SEM. Many processing technologies have been employed to obtain porous ceramics for bone tissue engineering. In tissue repair application the macro pores and highly interconnected networks are required for in-growth of surrounding host tissues. The milled powder was mixed with surfactant and finally press injection method was applied to make small diameter fillers. As a first parameter of biocompatibility [9] the ability of the cells to attach to the material surface during the early period of cell/material interaction was used. Then the powders were screened in vitro for cytotoxic [10] effects on cultured RAW macrophage cells. Cell attachment [11] study was observed under inverted microscopic analysis. Cytotoxicity effects were analyzed by Trypan blue staining method.

\section{EXPERIMENTAL PROCEDURE}

\subsection{Synthesis of Hydroxyapatite Powder from Fish Scale}

Fish scales were collected from fresh water fish (Labeo rohita) and washed thoroughly in running tap water. The collected scales were initially de-proteinized through external washing with $1(\mathrm{~N}) \mathrm{HCl}($ Merck, 35\%) solution (2:1, v/w, water $\mathrm{HCl} /$ fish scale) for 24 hours at room temperature $\left(25^{\circ} \pm 2^{\circ} \mathrm{C}\right)$. Next, the de-proteinized fish scales were washed thoroughly several times with distilled water. Remaining proteins of fish scales were treated with $1(\mathrm{~N}) \mathrm{NaOH}$ solution. The filtered fish scales were washed thoroughly with distilled water and dried at $60^{\circ} \mathrm{C}$ in hot air oven for several hours. Treated fish scales were calcined at different temperatures to synthesize HAp ceramics.

\subsection{Synthesis of Hydroxyapatite Powder from Bovine Bone}

Bovine bone were initially deproteinized externally with 1 (N) $\mathrm{HCl}$ (Merck, 35\%) solution and finally $1(\mathrm{~N}) \mathrm{NaOH}$ solution was added for removal of remaining proteins. The samples were then thoroughly washed with double distilled water and dried at $50-60^{\circ} \mathrm{C}$ at hot air oven. The dried samples were then calcined in air atmosphere for an hour at different temperatures viz. $1000^{\circ} \mathrm{C}, 1100^{\circ} \mathrm{C}$ and $1200^{\circ} \mathrm{C}$ to obtain HAp phase.

\subsection{Preparation of Small Fillers}

The synthesized powder was mixed with starch and milled for 48 hours in ball mill. Triton $-\mathrm{X}$ surfactant was added drop-wise with the powder to make a paste. Injection press method was employed to make small $2 \mathrm{~mm}$ diameter and $4 \mathrm{~mm}$ long fillers with this paste. The small rod 
shaped fillers were then dried at $80^{\circ} \mathrm{C}$ for several hours. Finally, the dried samples were sintered at $1100^{\circ} \mathrm{C}$ for two hours.

\section{POWDER CHARACTERIZATIONS}

The Thermo Gravimetric and Differential Thermal Analysis of HAp from treated fish scale and bovine bone was carried out using Thermal analyzer (Netzsch, STA 409) over a temperature range of $30^{\circ} \mathrm{C}-1250^{\circ} \mathrm{C}$ and heating rate of $10^{\circ} \mathrm{C} / \mathrm{min}$ under air atmosphere. The crystalline phases of synthesized powders were identified by X- ray diffraction analysis (Shimadzu, XRD-6000, $\mathrm{CuK} \alpha$ radiation). FTIR (Shimadzu) analysis of calcined powder at different temperatures were carried out to confirm the structural composition. The average particle sizes of powder samples were observed through SEM analysis. The optimized calcined HAp powder derived from fish scales were wet ball milled for several hours and compacted into cylindrical/square shapes. Cytotoxicity and cell attachment studies of synthesized HAp materials were also carried out in RAW macrophage like cell line media.

\section{RESULTS AND DISCUSSION}

\subsection{TG DTA Analysis}

The thermo gravimetric analysis (Fig.1.) of chemically treated fish scales were carried out between $35^{\circ} \mathrm{C}$ and $1250^{\circ} \mathrm{C}$ in air at a heating rate of $10^{\circ} \mathrm{C} / \mathrm{min}$. In this analysis actual weight losses [12-13] are observed in three steps and the related temperature ranges are $30^{\circ} \mathrm{C}-800^{\circ} \mathrm{C}$. The first loss is due to the weakly entrapped water in the sample material, the second and third losses resulted from the decomposition and burning of organic components in the raw scales. As the washing treatment could not completely remove the organic compounds of the inner parts of scale structure, the large weight loss is resulted mainly from those organics. However, there was minor weight loss on heating up to $1250^{\circ} \mathrm{C}$ which indicates thermal stability of the sample in this range.

The thermo gravimetric analysis (Fig.2.) of chemically treated bovine bone was carried out from room temperature to $1250^{\circ} \mathrm{C}$ in air atmosphere at a heating rate of $10^{\circ} \mathrm{C} / \mathrm{min}$. In this analysis, actual weight losses were observed with rising temperature. The first loss is due to the removal of trapped water in the sample material, the second and third losses resulted from the decomposition and burning of organic components in the bovine bone constituents. However, minor weight loss was observed on heating up to $1250^{\circ} \mathrm{C}$. 


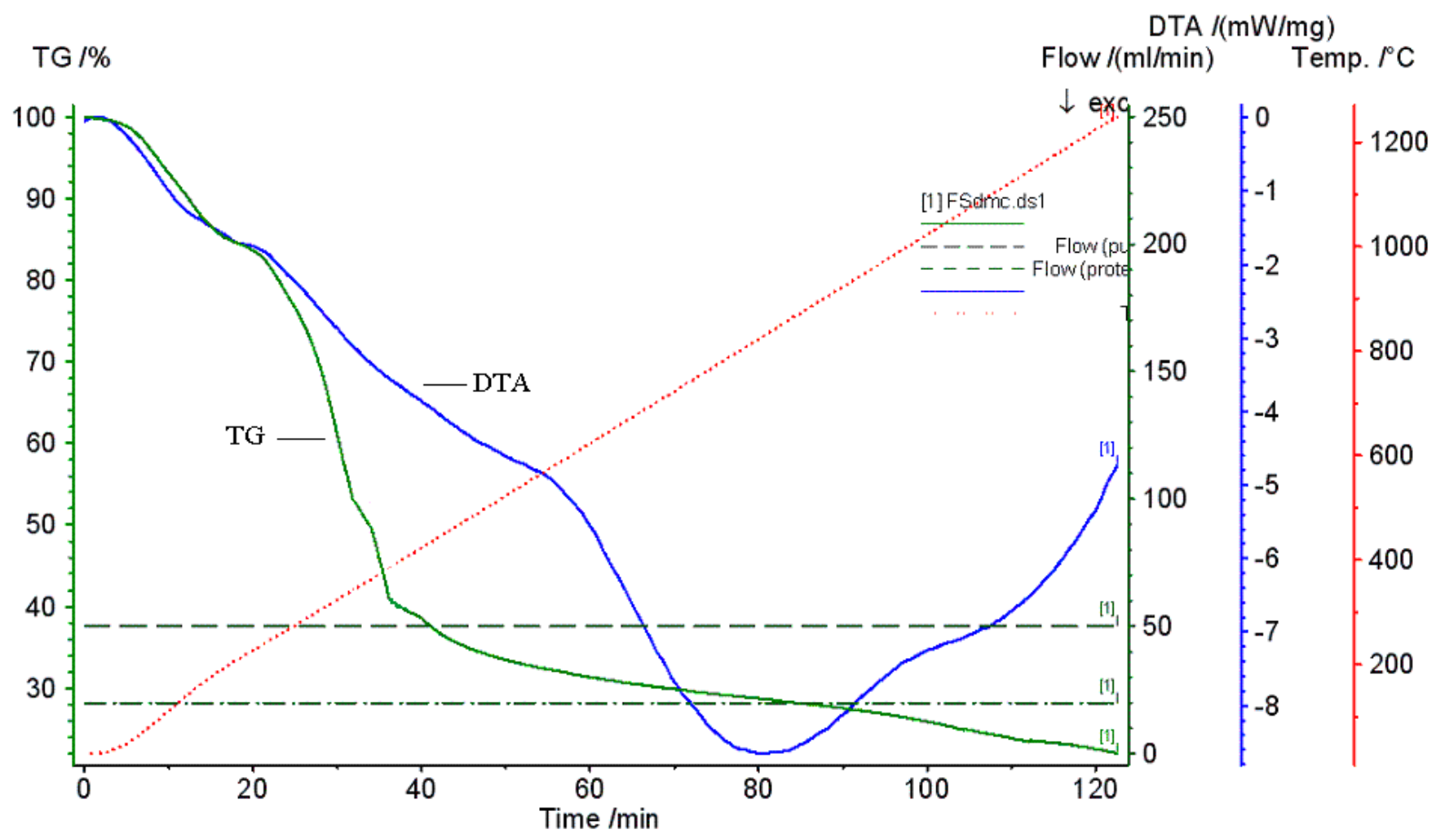

Fig. 1. TG DTA of Fish scale

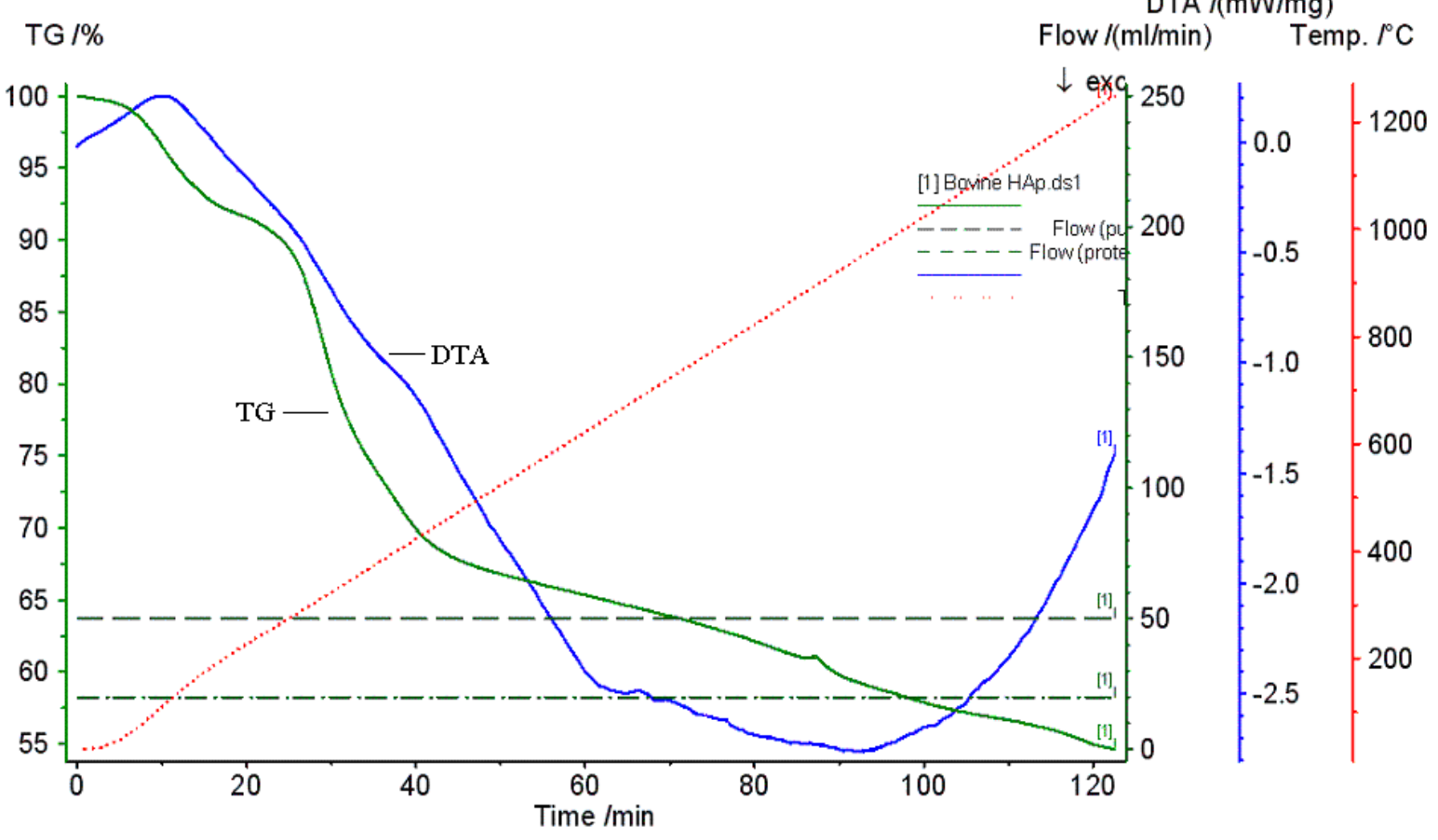

Fig. 2. TG DTA of Bovine bone 


\subsection{XRD Analysis}

XRD patterns of synthesized HAp particles from fish scales and bovine bone are shown in Fig. 3 and 4 respectively. The crystalline phase analysis of the HAp powder from two different bio sources were carried out by x-ray diffraction studies. Identification of the phases was realized by comparing the experimental XRD pattern to standards complied by the International Centre for Diffraction Data (ICDD) using the cards 00-009-0432 for hexagonal HAp structure. Each pattern showed HAp as the only phase. Well-resolved characteristic peak of highest intensity for HAp was obtained at $2 \theta$ value of $31.77^{\circ}$ corresponding to 211 plane. The phase formed was pure and matches well with standard pattern. The standard corresponding plane for HAp (viz. 100,101, 200, 002, 211, 202, 301, 130, 131, 113, 203, 222, 132, 321, 004, 240, 241, 502, 323, 511) are well observed in case of both the synthesized powders. Sharp peak intensity and well resolved peaks in XRD patterns of the powders at high calcination temperature proves complete crystallization of the powder. The crystallite sizes of HAp particles were calculated using Scherer's equation$$
\mathbf{D}=0.9 \lambda / B \cos \theta
$$

[Where, D represents mean grain size, B stands for full width at half maximum of the peak, $\lambda$ is the diffraction wavelength $(0.154059 \mathrm{~nm})$ and $\theta$ is the diffraction angle]

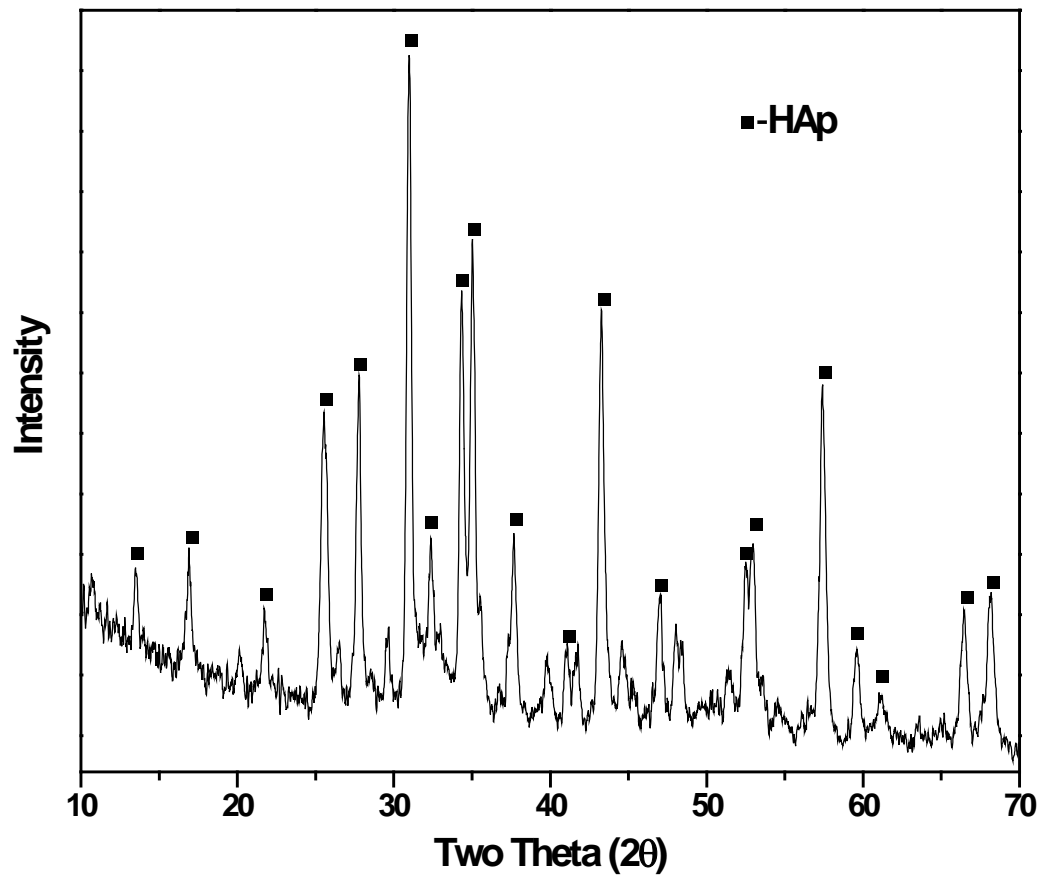

Fig. 3. XRD Pattern of synthesized HAp powder from Fish scale 


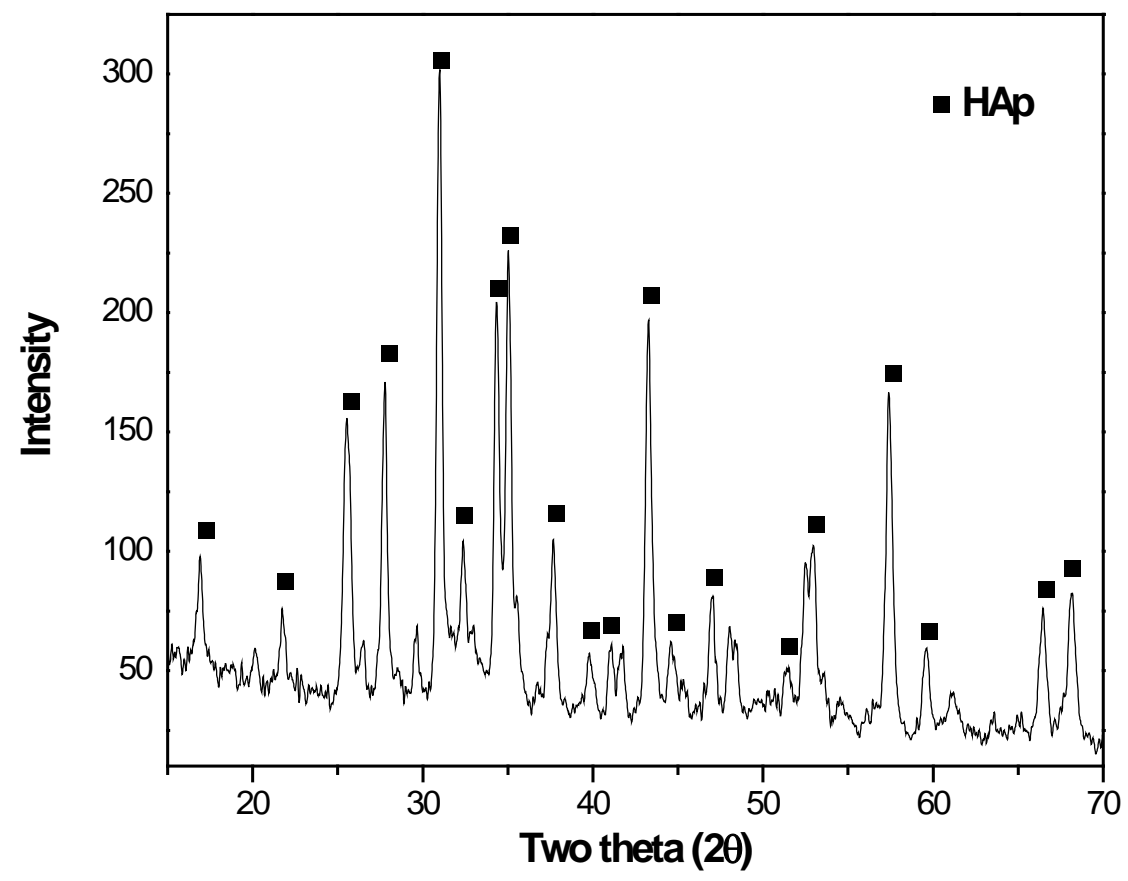

Fig. 4. XRD pattern of Hydroxyapatite powder from Bovine bone

The Bragg reflection at (002) planes of HAp was considered to calculate the crystallite size. Crystallite size for HAp synthesized from fish scales and bovine bones are $69.6 \mathrm{~nm}, 77.62 \mathrm{~nm}$ respectively.

\subsection{FTIR Analysis}

Fourier transform infrared (FTIR) spectroscopy was employed to characterize the different functional groups of HAp $\mathrm{Ca}_{10}\left(\mathrm{PO}_{4}\right)_{6}(\mathrm{OH})_{2}$, (HAp) powder obtained from two bio sources. Figures 5 and 6 show the FTIR spectrum of synthesized HAp from fish scales and cow bone, respectively. The spectrum was recorded in the range of $4000-400 \mathrm{~cm}^{-1}$. The representative FTIR spectrum shows all characteristic absorption peaks of HAp. The first indication for formation of HAp is in the form of a strong complex broad FTIR band centered at about 1000$1100 \mathrm{~cm}^{-1}$ due to asymmetric stretching mode of vibration for $\mathrm{PO}_{4}$ group [14]. The band at $576.30 \mathrm{~cm}^{-1}$ corresponds to $\mathrm{n} 4$ symmetric P-O stretching vibration of the $\mathrm{PO}_{4}$ group [15]. As a major peak of phosphate group, the $n 3$ vibration peak could be identified in the region between 1100- $960 \mathrm{~cm}^{-1}$ for all two powders which are due to $\mathrm{P}-\mathrm{O}$ asymmetric stretching of $\mathrm{PO}_{4}{ }^{3-}$. The band at 2005-2079 $\mathrm{cm}^{-1}$ is due to overtone of $1040 \mathrm{~cm}^{-1}$ band. The presence of peak in the region $1400 \mathrm{~cm}^{-1}-1450 \mathrm{~cm}^{-1}$ was due to absorbed carbon dioxide. The crystalline powder generates two characteristic stretching modes of $\mathrm{O}-\mathrm{H}$ bands at about $3497 \mathrm{~cm}^{-1}$ and $456 \mathrm{~cm}^{-1}$ which are notice in all FTIR spectra of HAp. 


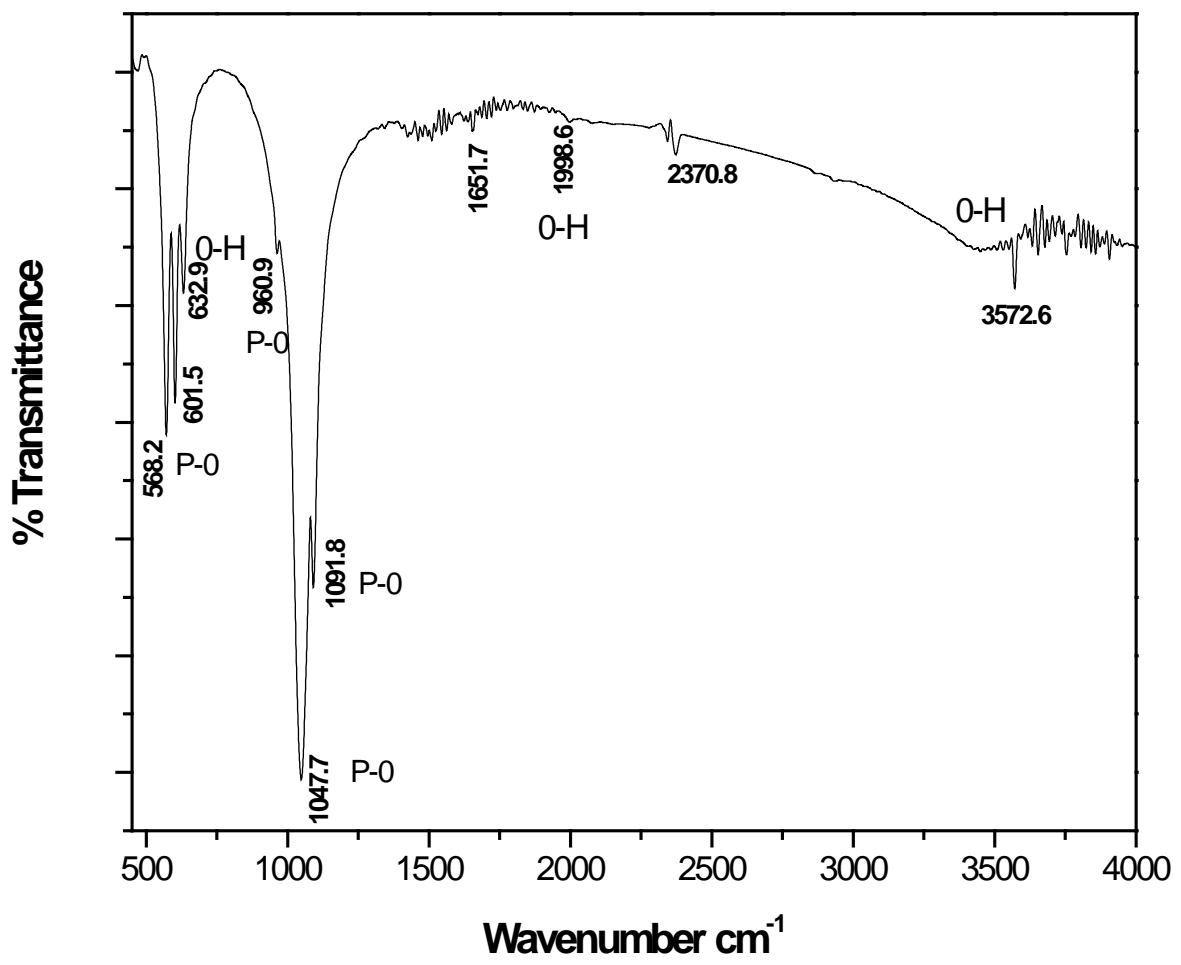

Fig. 5. FTR Spectrum of Hydroxyapatite powder from Fish scale

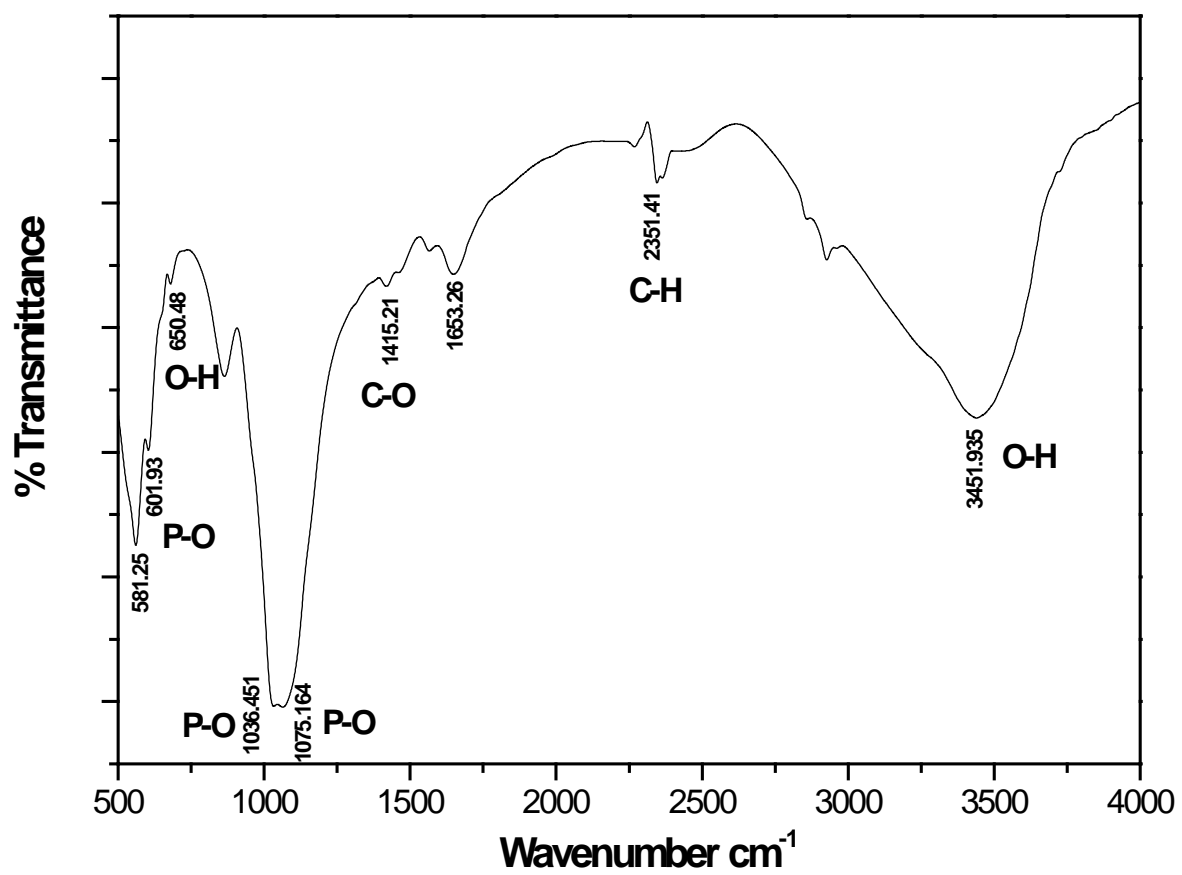

Fig. 6. FIR spectrum of Hydroxyapatite powder from Bovine bone 


\subsection{SEM Analysis}

The SEM micrographs of synthesized HAp powder (Fig. 7, 8) from fish scale and bovine bone sources were soft agglomerated ultra fine HAp particles which break up easily during compaction due to high uniform pressure.

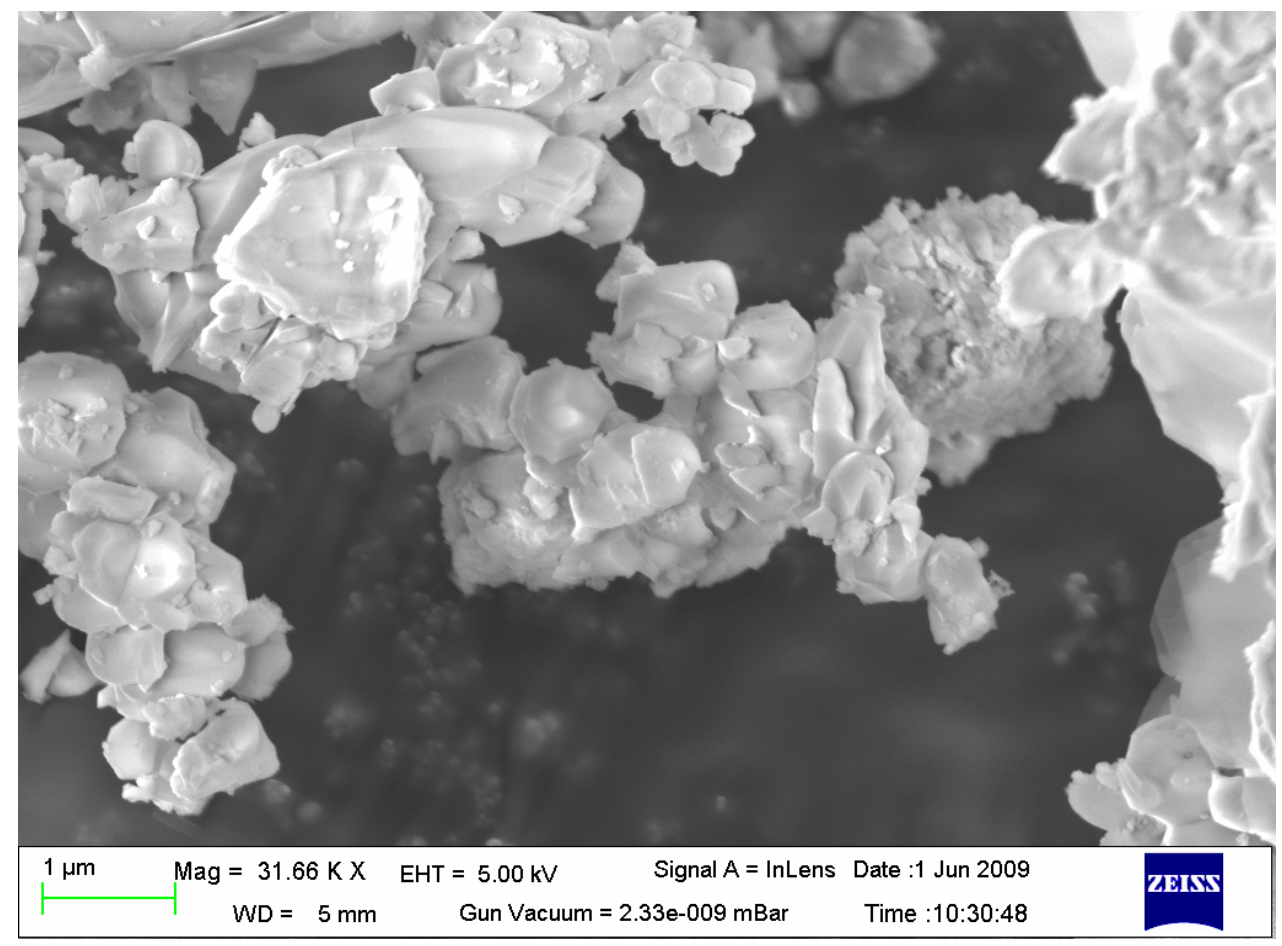

Fig.7. FE-SEM of HAp powder synthesized from Fish Scale 


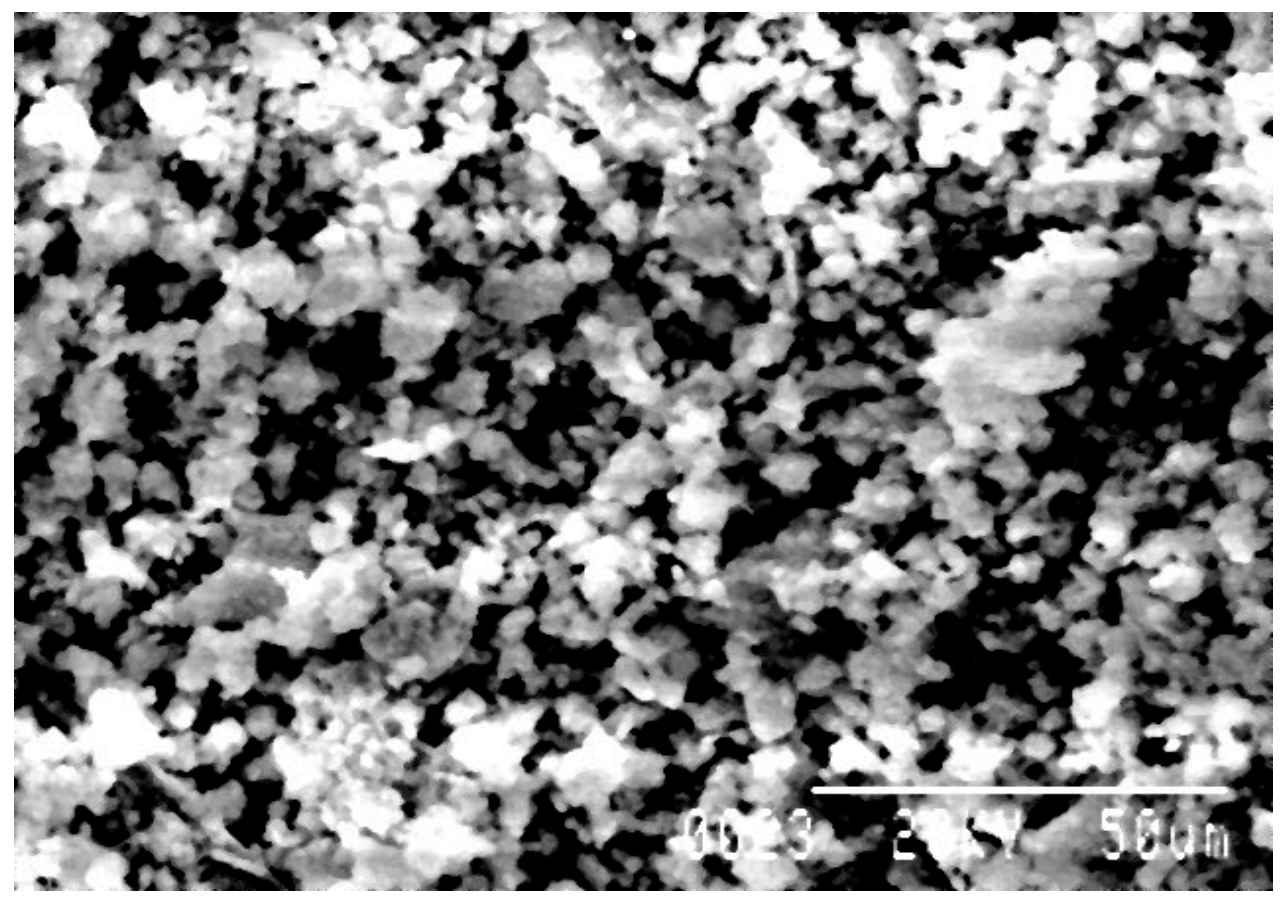

Fig. 8. FE-SEM of HAp powder synthesized from Bovine Bone

\subsection{Bio Fillers Made Up of Hap Powder}

The synthesized powder was wet ball milled for several hours and by using surfactants like Triton-X small fillers were made for bio implants. These small fillers were then sintered at $1100^{\circ}$ $\mathrm{C}$ temperature and prepared for in vivo bio implantation (Fig. 9 [a] and 9 [b]) and subsequent toxicity testing. The porosity of the sintered body in all the cases was around $10-15 \%$.

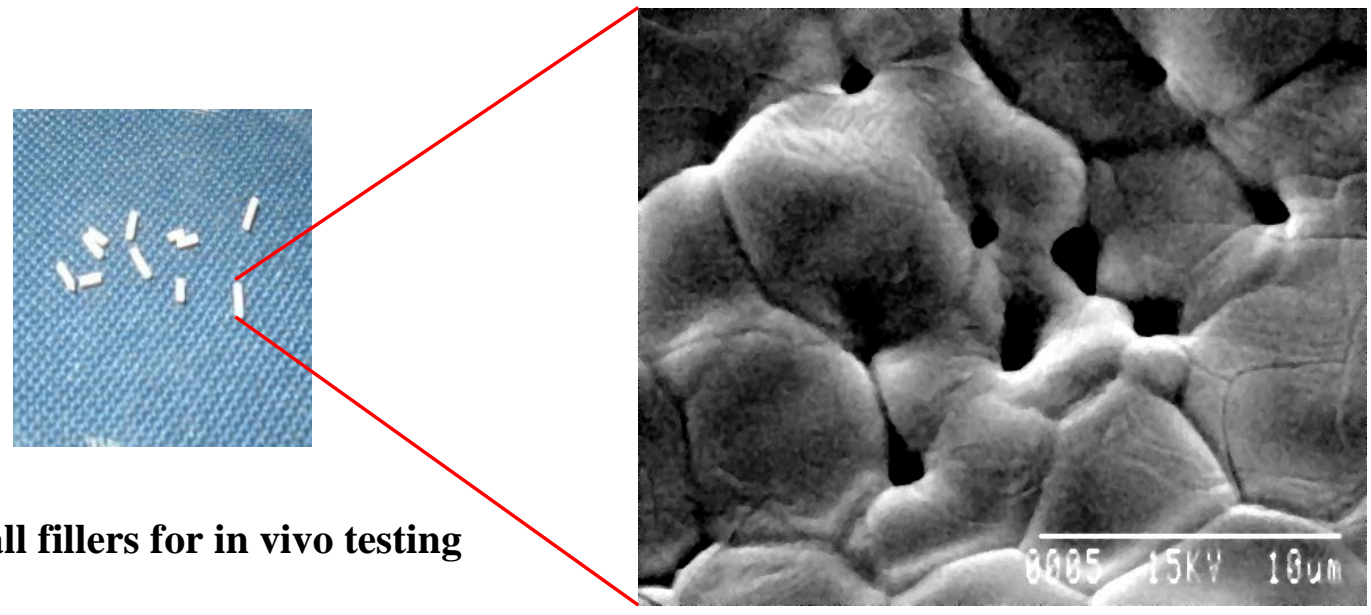

Fig. 9 (b). SEM image of the small fillers 


\subsection{In vitro Analysis}

HAp Powder samples as well as fillers and plates were utilized for further in vitro testing. First of all samples were sterilized by autoclaving at $16 \mathrm{lb} /$ inch $^{2}$ pressure for 20 minutes. Then the samples were placed into RPMI culture media. Here RAW cell lines were utilized for experimental purpose. Cell loads were given $10^{5}$ cells/ 200 micro litre. After incubation in cell culture media samples are stained and observed under inverted microscopy. Fig. 10, 11 and 12 show HAp particles incubated for 72 hours along with macrophage like RAW cell lines. The cultured cells were stained with Trypan Blue and the result shows that there are no dead cells in the culture vessels. It confirms that there is no toxic effect of the synthesized HAp materials.

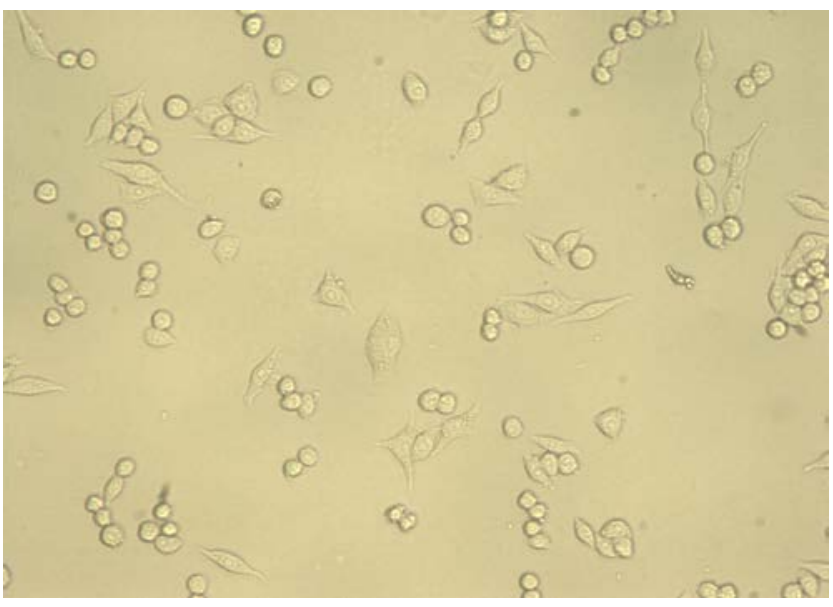

Fig.10. RAW cell line control media

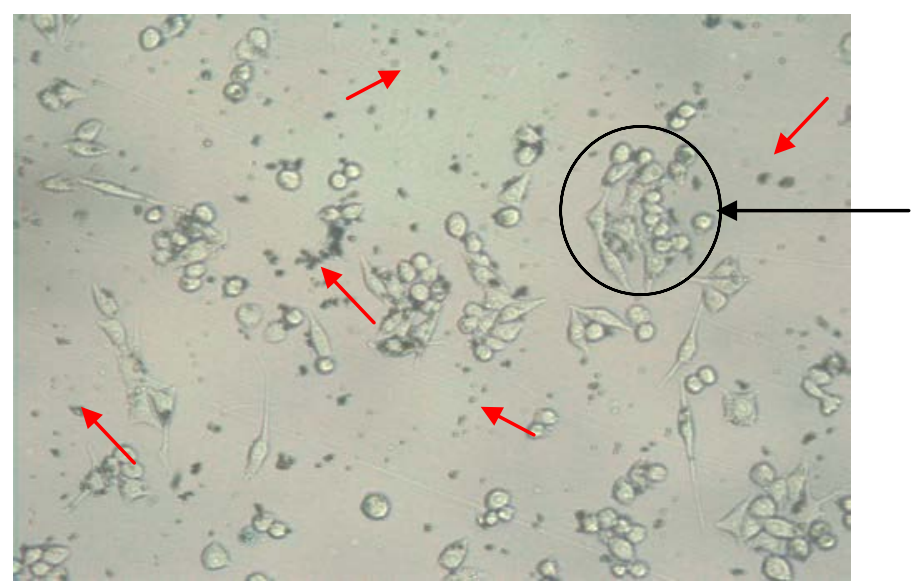

Fig.12. RAW cell line with Bovine bone derived HAp particles (red arrow)

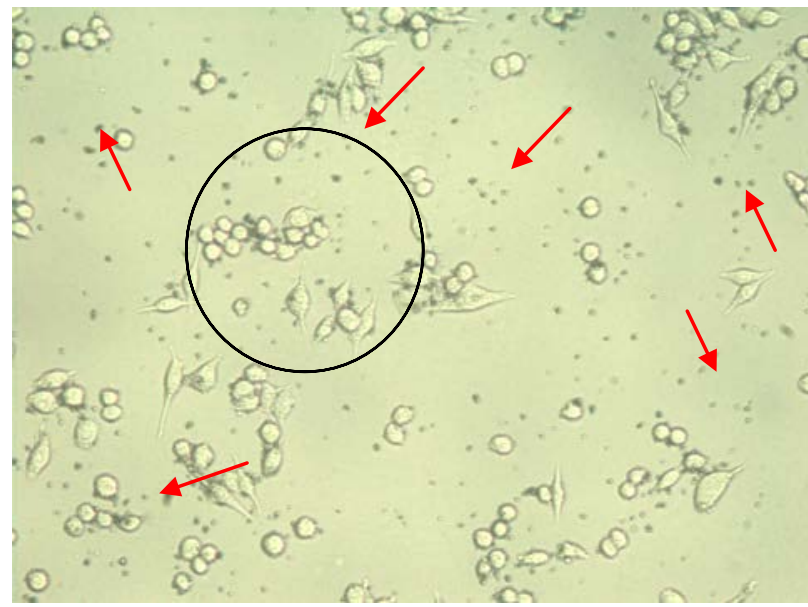

Fig.11. RAW cell line with Fish scale derived HAp particles (red arrow)

Viable cells and HAp particles (Inside circle) are shown adjacently in Fig. 11 and 12. It proves that synthesized HAp particles don't show any toxic effect on cell line. 


\section{CONCLUSIONS}

The present study reveals that HAp powder can be synthesized by thermal decomposition using fish scale and bovine bone in an eco-friendly manner. FTIR, X- ray diffraction and EDX analysis indicated the phase purity and crystallinity of the HAp powder. TG-DTA analysis results showed the thermal stability of HAp powder derived from these two different biosources. The microstructural study of compacted powders show the presence of uniformly distributed very fine submicron particles. HAp ceramic fillers prepared from Injection press method are found to exhibit $30 \%$ porosity, which could be useful for biomedical applications such as fillers or scaffold. These small biocompatible osteo-conductive fillers appear to have a great potential for bone tissue engineering. The small biocompatible osteo-conductive fillers appear to have great potential for bone tissue engineering as they showed no toxic effect on cell culture studies. More systematic studies are required for the characterization and in vivo, in vitro assessments of bioceramic composite scaffolds for bone tissue engineering.

\section{ACKNOWLEDGEMENT}

The authors would like to express their gratitude to Prof. Gautam Biswas, Director, CMERI for his kind permission to present this paper. The authors are also grateful to CSIR, Govt. of India, for the financial support through networking projects. The authors are also thankful to Dr. Syamal Roy and all the staff members of Infectious Diseases \& Immunology Division, IICB, Kolkata, for their cell culture and cytotoxicity studies and Mr. P. Dhak, Mr. A. Paria and Mr. B. Das of IIT, Kharagpur for thermal, FE- SEM and XRD studies.

\section{REFERENCES}

[1] Mobasherpour, I., Heshajin, M. S., Kazemzadeh, A., M. Zakeri, M., 2007, “'Synthesis of Nanocrystalline Hydroxyapatite by using Precipitation Method,’' J. Alloys Compd., Vol. 430, pp. 330-333.

[2] Parthiban, S.P., Elayaraja, K., Girija, E. K., Yokogawa, Y., Kesavamoorthy, R., Palanichamy, M., Asokan, K., and Narayana Kalkura, S., 2009, "Preparation of thermally stable nanocrystalline hydroxyapatite by hydrothermal method.” J. Mater. Sc: Mater. Med., Vol. 20, pp. 77-83.

[3] Kim, W., Zhang, Q., and F. Saito., 2000, "Mechanochemical synthesis of hydroxyapatite from $\mathrm{Ca}(\mathrm{OH}) 2-\mathrm{P} 2 \mathrm{O} 5$ and $\mathrm{CaO}-\mathrm{Ca}(\mathrm{OH}) 2-\mathrm{P} 2 \mathrm{O} 5$ mixtures.” J. Mater. Sci., Vol. 35, pp. 54015405.

[4] Balamurugan, A., Kannan, S., and Rajeswari S., 2002, "Bioactive sol-gel hydroxyapatite surface for biomedical applications-in vitro study.” Trends. Biomater. Artif. Organs, Vol. 16, pp. 18-20. 
[5] Tadic D., and. Epple, M., 2003, "Mechanically stable implants of synthetic bone mineral by cold isostatic pressing.”, Biomaterials, Vol. 24, pp. 4565-4571.

[6] Mondal, S., Mahata, S., Kundu, S., and Mondal, B., 2010, "Processing of natural resourced hydroxyapatite ceramics from fish scale.” Adv. Appl.Ceram.: Struct. Funct. Bioceram., Vol. 109, pp. 234-239.

[7] Sastry T.P., Sankar S., Mohan R., Rani S., Sundaraseelan T., 2008, "Preparation and partial characterization of collagen sheet from fish (Lates calcarifer) scales” International Journal of Biological Macromolecules, Vol. 42, pp. 6-9.

[8] Kalita, S.J., Bhardwaj, A., Bhatt, H.A., 2007, "Nanocrystalline calcium phosphate ceramics in biomedical engineering.” Materials Science and Engineering: C, Vol. 27 Issue 3, pp. 441449.

[9] Liao, C. J., Lin, F. H., Chen, K. S., and J. S. Sun., J.S., 1999, “Thermal decomposition and reconstitution of hydroxyapatite in air atmosphere.” Biomaterials, Vol. 20, pp. 1807-1813.

[10] Roy, M., Krishna, B V., Bandyopadhya, A., Bose, S., 2011, “Compositionally graded hydroxyapatite/tricalcium phosphate coating on Ti by laser and induction plasma.” Acta Biomaterialia, Vol. 7, pp. 866-873.

[11] Stok, J. V. der, Lieshout, E. M. M. V., Massoudi, Y. E., Gerdine H. Van Kralingen, G. H. V., and Patka, P., 2011, "Bone substitutes in the Netherlands - A systematic literature review” Acta Biomaterialia., Vol. 7 , pp. 739-750.

[12] Mortier, A., Lemaitre, J., and Rouxhet, P.G., 1989, “Temperature programmed characterization of synthetic calcium deficient hydroxyapatite.” Thermochim. Acta,, Vol. 143, pp. 265-282.

[13] Ozawa, M., Suzuki, S., 2002 "Microstructural Development of Natural Hydroxyapatite Originated from Fish-Bone Waste through Heat Treatment.” J. Am. Ceram. Soc., Vol. 85, pp. 1315-1317.

[14] Rocha, J. H. G., Lemos, A.F., Kannan, S., Agathopoulos, S., Ferreira, J. M. F., 2005, "Hydroxyapatite scaffolds hydrothermally grown from aragonitic cuttlefish bones", Journals of Materials Chemistry, Vol. 15, pp. 5007-5011.

[15] Varma, H.K., and Babu, S., 2005. "Synthesis of Calcium Phosphate Bioceramics by Citrate Gel Pyrolysis Method.” Ceram. Int., Vol. 31, pp. 109-114. 